\title{
Comparison of miconazole-coated tampons with clotrimazole vaginal tablets in the treatment of vaginal candidosis
}

\author{
MICHAEL J BALSDON \\ From the Department of Genitourinary Medicine, St Mary's Hospital, Portsmouth, Hants
}

SUMMARY The effectiveness and acceptability of miconazole-coated tampons were compared with those of clotrimazole vaginal tablets in the treatment of vaginal candidosis in 100 women. Both treatments were highly effective in reducing the signs and symptoms of infection; $95 \%$ of the group treated with miconazole had negative culture results for Candida species immediately after treatment compared with $86 \%$ of those treated with clotrimazole. A $17 \cdot 6 \%$ recurrence rate of positive culture results was found four weeks later in the miconazole-treated group compared with that of $30 \%$ in the clotrimazole-treated group. The miconazole tampons were highly acceptable to patients. Vaginal $\mathrm{pH}$ values did not differ significantly between those patients with candidosis and those treated and cured. Corynebacterium vaginale (Gardnerella vaginalis) vaginitis and nonspecific genital infection were common complicating factors during follow up.

\section{Introduction}

Miconazole-coated tampons (Gyno-Daktarin tampons, Janssen Pharmaceutical Ltd) have recently become available in Britain for the treatment of vaginal candidosis. An initial multicentre open study using these tampons ${ }^{1}$ showed clinical and mycological cure rates which were similar to those reported for miconazole pessaries and clotrimazole tablets. ${ }^{2}$ This study also showed that the coated tampons were highly acceptable to patients, who preferred them to the other forms of treatment in use for vaginal candidosis.

This single-blind randomised trial assessed and compared the therapeutic effectiveness and acceptability to patients of miconazole-coated tampons with those of clotrimazole vaginal tablets in the treatment of vaginal candidosis. This is the first study of miconazole-coated tampons that provides a randomised comparison with clotrimazole. ${ }^{3}$

\section{Patients and methods}

One hundred women with vaginal candidosis were studied. All had vulval pruritus, with or without vaginal discharge, and Candida species were present

Address for reprints: Dr M J Balsdon, Department of Genitourinary Medicine, St Mary's Hospital, Portsmouth, Hants PO3 6AD

Accepted for publication 13 February 1981 on microscopy of a Gram-stained vaginal smear. Patients with associated genitourinary infections and those who had used vaginal or oral antifungal treatments within the previous four weeks were excluded.

\section{CLINICAL FEATURES}

Clinical signs and symptoms of burning or soreness, pruritus, discharge, vulvitis, and vaginitis (described as absent, mild, moderate, or severe) were recorded at each visit.

\section{LABORATORY DIAGNOSIS}

The cervix was exposed with an unlubricated bivalve vaginal speculum. Specimens of vaginal discharge collected from the posterior and lateral fornices were stained by Gram's method, and material collected similarly on a charcoal-treated swab was placed in Stuart's medium for transport to the laboratory the following morning. Gram-stained smears of urethral and cervical secretion and vaginal wet films were examined microscopically to exclude trichomoniasis, Corynebacterium vaginale vaginitis, and gonorrhoea; routine cultures were made from these swabs. Vaginal pH was measured by applying indicator paper to the adherent secretions on the upper tip of the withdrawn vaginal speculum. The swabs in transport medium were subcultured in the laboratory on Sabouraud's medium and Candida species identified by standard laboratory procedures. 


\section{TREATMENT}

Treatment was randomised and blind to the observer. Each patient received either a five-day course of miconazole-coated tampons inserted twice daily or a six-day course of one clotrimazole vaginal tablet inserted daily. The two drugs were enclosed in numbered identical plain packs, each containing an instruction leaflet and a brief questionnaire. A tube of miconazole or clotrimazole cream for external use, as appropriate, was also included.

\section{FOLLOW UP}

Patients were asked to return for follow up after 7-10 days and then four weeks later. All clinical, microscopical, and microbiological studies were repeated at each visit. Cure was defined as the absence of Candida species from cultures. When treatment had failed, a course of miconazole pessaries (two inserted daily for seven days) was given. The code was broken at the end of the trial.

\section{STATISTICAL ANALYSIS}

The statistical methods used were $\chi^{2}$ tests with Yates's correction where numbers were small. Student's $t$ test was used in connection with the vaginal $\mathrm{pH}$ measurements.

\section{QUESTIONNAIRE}

The brief questionnaire to assess the acceptability to the patient, which was included with the treatment pack, was completed independently by the patient and brought to the first follow-up visit; a further, more detailed, questionnaire was then completed by the doctor in the presence of the patient.

Ethical approval for the study was given by the appropriate hospital committee.

\section{Results}

The two treatment groups were well matched for demographic data. Ages ranged from 17 to $\mathbf{4 5}$ years (median 23 years) in the miconazole-treated group and from 16 to 55 (median 22 years) in the clotrimazole-treated group. One patient in each group was pregnant. Thirty $(60 \%)$ of the miconazoletreated group and $32(64 \%)$ of the clotrimazoletreated group had a history of previous candidosis; $21(42 \%)$ of the former and $22(44 \%)$ of the latter were taking oral contraceptives.

Except for one patient from India and one from France in the miconazole-treated group, the patients were all of British origin.

\section{CLINICAL SIGNS AND SYMPTOMS}

Both treatments were highly effective in reducing the signs and symptoms of vaginal candidosis. Only three $(3 \cdot 5 \%)$ of the 86 patients attending the first
follow-up visit had moderate or severe symptoms and signs, and all three had positive culture results for $\ddot{\vec{*}}$ Candida species. Of these, two had been given clotrimazole tablets and one miconazole-coated tampons.

\section{CULTURES}

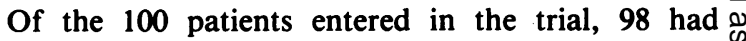
positive culture results for Candida species; of these, $86(87 \cdot 8 \%)$ were available for study at the first? follow up (table I). In the miconazole-treated group $\vec{\omega}$ $41(95 \cdot 3 \%)$ of 43 patients had negative culture results at the first follow-up visit. For the clotrimazole- $\stackrel{9}{=}$ treated group the apparent cure rate was $86 \%$ or (37/43).

TABLE I Results of treatment using miconazole-coated tampons and clotrimazole tablets

\begin{tabular}{|c|c|c|c|c|c|c|c|c|}
\hline \multirow[b]{4}{*}{ Treatment } & \multicolumn{8}{|c|}{ Culture results for Candida species at: } \\
\hline & \multicolumn{4}{|c|}{ First visit $(n=86)$} & \multicolumn{4}{|c|}{ Final visit $(n=64)$} \\
\hline & \multicolumn{2}{|c|}{ Negative } & \multicolumn{2}{|c|}{ Positive } & \multicolumn{2}{|c|}{ Negative } & \multicolumn{2}{|c|}{ Positive } \\
\hline & No & $\%$ & No & $\%$ & No & $\%$ & No & $\%$ \\
\hline $\begin{array}{l}\text { Miconazole- } \\
\text { coated tampons } \\
\text { Clotrimazole }\end{array}$ & 41 & $95 \cdot 3$ & 2 & $4 \cdot 7$ & 28 & $82 \cdot 4$ & 6 & $17 \cdot 6$ \\
\hline $\begin{array}{l}\text { tablets } \\
\text { Total }\end{array}$ & $\begin{array}{l}37 \\
78\end{array}$ & $\begin{array}{l}86 \cdot 0 \\
90 \cdot 7\end{array}$ & $\begin{array}{l}6 \\
8\end{array}$ & $\begin{array}{r}14 \cdot 0 \\
9 \cdot 3\end{array}$ & $\begin{array}{l}21 \\
49\end{array}$ & $\begin{array}{l}70 \cdot 0 \\
76 \cdot 6\end{array}$ & $\begin{array}{r}9 \\
15\end{array}$ & $\begin{array}{l}30 \cdot 0 \\
23 \cdot 4\end{array}$ \\
\hline
\end{tabular}

\section{RECURRENCE RATE}

Candidosis was considered to have recurred in those patients with positive culture results at the final visit after previous apparent cure. The recurrence rate was $17.6 \%(6 / 34)$ in the miconazole-treated group and $30 \%(9 / 30)$ in the clotrimazole-treated group (table I). These differences in the apparent cure and recurrence rates are not statistically significant.

\section{VAGINAL pH}

The vaginal pH measurements did not differ $D$ significantly between those patients with and without candidosis; 98 patients with candidosis had a mean $N$ vaginal $\mathrm{pH}$ of $4 \cdot 7(\mathrm{SD} \pm 0 \cdot 3)$, and 74 uninfected patients at first follow up and 53 at final follow up had a mean vaginal $\mathrm{pH}$ of $4 \cdot 6(\mathrm{SD} \pm 0 \cdot 3)$.

\section{OTHER DIAGNOSES}

Four patients $(4 \cdot 7 \%)$ had $C$ vaginale vaginitis with negative culture results for Candida species at the first follow up visit. They were cured with a five-day course of metronidazole $400 \mathrm{mg}$ twice daily; in one patient candidosis had recurred again at her final $\stackrel{\odot}{\mathcal{Q}}$ visit. At the final visit a further three patients had $C \stackrel{\mathbb{Q}}{\Omega}$ vaginale vaginitis (two of these also had positive $\sigma$ 
culture results for Candida species) and one patient had trichomoniasis, one gonorrhoea, and three nonspecific genital infection.

\section{ACCEPTABILITY OF TREATMENT}

Of the 62 patients who had had previous treatment for vaginal candidosis $51(82 \cdot 3 \%)$ completed the questionnaires. In the miconazole-treated group 19 $(66 \%)$ of 29 rated miconazole tampons as better or very much better than any previous treatment, whereas only seven $(32 \%)$ of 22 of the clotrimazoletreated group gave a similar rating. This difference is statistically significant $(P<0 \cdot 05)$.

When asked about the best or worst features of treatment, patients receiving miconazole tampons clearly regarded convenience and lack of mess as the best features. In the clotrimazole-treated group convenience was the most often selected best feature but a large majority considered messiness to be the worst. No particularly bad feature was identified by the patients in the miconazole-treated group. When asked to comment on the degree of messiness (as judged by the need for protective wear or a change of underwear), $77 \cdot 3 \%(34 / 44)$ of the patients in the clotrinazole-treated group considered the treatment to be slightly or very messy, whereas $17 \cdot 4 \%(8 / 46)$ found the miconazole tampons slightly messy, although none found them very messy. This difference is highly significant $(P<0 \cdot 0001)$. More detailed analysis of the questionnaires will be presented elsewhere.

\section{SIDE EFFECTS}

There were no serious adverse effects resulting from either regimen. Four patients in each group mentioned mild burning or irritation in the first few days of therapy.

\section{Discussion}

Infection with Candida species is the most common cause of vaginitis, is often recurrent, and appears to be increasing in incidence. Intravaginal antifungal therapy in the form of pessaries, tablets, and cream has always been unpopular with patients because of leakage of medication from the vagina, ${ }^{45}$ particularly when treatment continues for many days. Because of this, patients may discontinue treatment and fail to attend for follow up. ${ }^{6}$ The introduction of a five-day course of miconazole-coated tampons now offers a convenient and acceptable alternative.

The cure and recurrence rates in this trial are comparable with results recently published separately for miconazole-coated tampons ${ }^{1}$ and clotrimazole vaginal tablets ${ }^{2}$ (table II). The results for miconazole tampons compared favourably with those for miconazole pessaries and cream. ${ }^{78}$ The cure rates immediately after treatment were similar for the groups treated with miconazole-coated tampons and clotrimazole tablets. The recurrence rates, however, were lower in the miconazole-treated group but not significantly so in the present study.

TABLE II Comparison of cure and recurrence rates in three recent studies

\begin{tabular}{|c|c|c|c|c|}
\hline Study & Treatment & $\begin{array}{l}\text { No of } \\
\text { patients } \\
\text { treated }\end{array}$ & $\begin{array}{l}\text { Cure } \\
\text { rate* } \\
(\%)\end{array}$ & $\begin{array}{l}\text { Recurrence } \\
\text { ratet } \\
\text { (\%) }\end{array}$ \\
\hline \multirow{4}{*}{$\begin{array}{l}\text { Eliot }\left.e t a\right|^{2} \\
\text { Rosedale } e t a l^{1} \\
\text { Balsdon } \\
\quad \text { (present study) }\end{array}$} & \multirow{4}{*}{$\begin{array}{l}\text { Clotrimazole } \\
\text { vaginal tablets } \\
\text { Miconazole- } \\
\text { coated tampons } \\
\text { Clotrimazole } \\
\text { vaginal tablets } \\
\text { Miconazole- } \\
\text { coated tampons }\end{array}$} & 60 & $88 \cdot 7$ & $28 \cdot 3$ \\
\hline & & 195 & $88 \cdot 5$ & $12 \cdot 1$ \\
\hline & & 50 & $86 \cdot 0$ & $30 \cdot 0$ \\
\hline & & 50 & $95 \cdot 3$ & $17 \cdot 6$ \\
\hline
\end{tabular}

* Negative culture results for Candida species at first follow-up visit. tCured at the first follow-up visit but positive culture results at second follow-up visit.

Vaginal $\mathrm{pH}$ values did not differ significantly during or after vaginal candidal infection. Conflicting and confusing results, ${ }^{910}$ often due to a few high $\mathrm{pH}$ values, can possibly be explained by the inclusion in the data of patients with conditions such as $C$ vaginale vaginitis, in which $\mathrm{pH}$ values are invariably $5 \cdot 3$ and above. ${ }^{11}$ The great majority of patients with vaginal candidosis have vaginal $\mathrm{pH}$ values in the normal range of $4 \cdot 2-5 \cdot 0$ (unpublished data).

Seven patients developed $C$ vaginale vaginitis during the trial. Until recently this condition has not often been diagnosed in Britain. "Its presence may account for a proportion of those patients with candidosis who are apparently cured but still have discharge and irritation. Davidson and Mould ${ }^{12}$ found a high incidence of non-specific genital infection in their group of patients with candidosis. Non-specific genital infection and $C$ vaginale vaginitis were also found in patients followed up during this study.

The miconazole-coated tampons were highly acceptable to patients, as treatment lasts for only five days and there is no leakage of medication from the vagina. This latter aspect was regarded by most patients as the best feature of miconazole-coated tampons and the worst feature of clotrimazole vaginal tablets. A further advantage of tampons is that most women are accustomed to using them routinely during menstruation. Several women commented that they always used menstrual tampons to avoid the leakage from vaginal pessaries and creams. Miconazole-coated tampons thus provide a valuable contribution to the management of a common, recurrent, and troublesome condition. 
I thank all the staff and patients for their help and co-operation, $\operatorname{Dr} \mathrm{O}$ A Okubadejo, consultant microbiologist, for laboratory help, and Janssen Pharmaceutical Limited for materials and statistical analysis.

\section{References}

1. Rosedale N, Balsdon MJ, Cree GE, Mayhew SR. An open multicentre assessment of the efficacy and patient acceptability of miconazole-coated tampons in the treatment of vaginal candidosis. Curr Ther Res 1980;27:493-7.

2. Eliot BW, Howat RCL, Mack AE. A comparison between the effects of nystatin, clotrimazole and miconazole on vaginal candidiasis. Br J Obstet Gynaecol 1979; 80:572-7.

3. Odds FC. Candida and Candidosis. Leicester: Leicester University Press. 1979.
4. Higton BK. A trial of clotrimazole and nystatin in vaginal moniliasis. J Obstet Gynaecol Br Commonwealth 1973;80: 992-5.

5. Morese KN. Candicin tablets and ointment in treatment of candidal vaginitis. $N$ Y State J Med 1975; 75: 1443-5.

6. Masterton G, Henderson J, Napier IR, Moffett M. Vaginal candidosis. Br Med J 1976; i: 712-3.

7. Sawyer PR, Brogden RM, Pinder RM, Speight TM, Avery GS. Miconazole: a review of its antifungal activity and therapeutic efficacy. Drugs 1975;9:406-23.

8. Reyntjens A. New gynaecological formulations of miconazole. RSM International Symposium \& Congress Series 1979;7: 25-30.

9. Drake SM, Evans BA, Gerken A. Vaginal pH and microflora related to yeast infections and treatment. Br J Vener Dis 1980; 56: 107-10.

10. Peeters F, Snauwaert R, Segers J, van Cutsen J, Amery W. Observations on candidal vaginitis. Am J Obstet Gynecol 1972; 112:80-6.

11. Balsdon MJ, Taylor GE, Pead L, Maskell R. Corynebacterium vaginale and vaginitis: a controlled trial of treatment. Lancet or 1980; i: 501-4.

12. Davidson F, Mould RF. Recurrent genital candidosis in women is and the effect of intermittent prophylactic treatment. $B r J N$ Vener Dis 1978; 54: 176-83. 